\title{
Usage and Diagnostic Yield of Fine-Needle Aspiration Cytology and Core Needle Biopsy in Thyroid Nodules: A Systematic Review and Meta-Analysis of Literature Published by Korean Authors
}

\author{
Soon-Hyun Ahn (iD \\ Department of Otorhinolaryngology-Head and Neck Surgery, Seoul National University Hospital, Seoul National University College of Medicine,
}

Seoul, Korea

Objectives. The usefulness of core needle biopsy (CNB) for the diagnosis of thyroid nodules remains controversial, and preferences vary across hospitals. The purpose of this study was to assess the actual use of CNB in Korea and to analyze the advantages and disadvantages of CNB through a systematic review and meta-analysis of papers published by Korean authors.

Methods. A meta-analysis of full-text publications published in English presenting data from Korea retrieved from the Embase literature database was performed.

Results. CNB led to a significantly lower proportion of non-diagnostic results than fine-needle aspiration (FNA). However, the frequency of atypia of undetermined significance/follicular lesion of undetermined significance (AUS/FLUS) did not decrease as a result of performing CNB in nodules with initial AUS/FLUS results, while it increased in consecutive cases. A subcategory analysis of AUS/FLUS showed that the increased frequency of AUS/FLUS findings on CNB was due to more frequent diagnoses of architectural atypia and follicular neoplasm, which resulted in a higher frequency of inconclusive findings in consecutive cases compared to FNA. Hospitals favoring CNB had a higher proportion of AUS/FLUS diagnoses. Although the complication rate did not differ significantly between CNB and FNA, serious complications of CNB did occur.

Conclusion. A reduced frequency of non-diagnostic results may be a definite advantage of CNB over FNA. However, the increased frequency of diagnoses of architectural atypia and follicular neoplasm should be considered when selecting $\mathrm{CNB}$ as a diagnostic tool.

Keywords. Thyroid Nodule; Core Needle Biopsy; Aspiration Biopsies, Fine Needle; Thyroid Carcinoma

\section{INTRODUCTION}

Core needle biopsy (CNB) has been used for thyroid nodules in Korea since the mid-to-late 2000s, and a paper published in 2011

- Received February 12, 2020

Revised March 19, 2020

Accepted March 19, 2020

- Corresponding author: Soon-Hyun Ahn

Department of Otorhinolaryngology-Head and Neck Surgery, Seoul

National University Hospital, 101 Daehak-ro, Jongno-gu, Seoul 03080,

Korea

Tel: +82-2-2072-3649, Fax: +82-31-787-4057

E-mail: ahnsh30@snu.ac.kr was the first to assess the role of CNB in thyroid nodules [1]. Thereafter, various hospitals in Korea-especially Asan Medical Center-have published studies suggesting that CNB is advantageous over fine-needle aspiration (FNA) cytology. However, at academic meetings, we have encountered discordant opinions across hospitals regarding the role of $\mathrm{CNB}$, with some practitioners feeling that $\mathrm{CNB}$ offers enough advantages to be considered as the first-line modality for biopsy and others believing that CNB confers no advantage over FNA. Previous meta-analyses of CNB evaluated its diagnostic accuracy based on its sensitivity or specificity for the diagnosis of malignancy or focused on specific conditions, such as nodules with non-diagnostic or atypia

Copyright () 2021 by Korean Society of Otorhinolaryngology-Head and Neck Surgery.

This is an open-access article distributed under the terms of the Creative Commons Attribution Non-Commercial License (https://creativecommons.org/licenses/by-nc/4.0)

which permits unrestricted non-commercial use, distribution, and reproduction in any medium, provided the original work is properly cited. 
of undetermined significance/follicular lesion of undetermined significance (AUS/FLUS) results on previous FNA [2-11]. Therefore, there are limitations in the degree to which we understand the difference between CNB and FNA in real clinical settings based on those meta-analyses.

This systematic review and meta-analysis included all articles on CNB and/or FNA in thyroid nodules published by Korean authors to analyze the frequency of various Bethesda System for Reporting Thyroid Cytopathology (TBSRTC) categories. The purpose of this study was, through a comprehensive review of consecutive data from Korea, to determine the circumstances in which hospitals favor CNB or FNA and to compare differences in results between CNB and FNA, with the goal of clarifying expectations related to the choice of a biopsy modality in Korea.

\section{MATERIALS AND METHODS}

\section{Literature search}

The Embase database was searched on September 18, 2019, using the terms " "thyroid'/exp OR thyroid" AND ("fine needle aspiration" OR "core needle biopsy") AND "Korea."

\section{Inclusion criteria}

The inclusion criteria were: (1) full-text original articles in English published by Korean authors, (2) presenting data from a specific hospital, (3) frequency of diagnoses reported using consecutive cases, and (4) results on thyroid nodules, especially differentiated thyroid carcinoma. Conference articles, reviews or meta-analyses, and articles reporting multi-center data were excluded. FNA findings were analyzed based on the TBSRTC, while CNB data were analyzed based on the proposal of the Korean Endocrine Pathology Thyroid Core Needle Biopsy Study Group [12]. However, the reporting system proposed by the Korean Study Group uses the same system as TBSRTC, and the only difference is that AUS/FLUS in TBSRTC is expressed as an indeterminate lesion in the Korean Study Group proposal. In this paper, indeterminate results on CNB are collectively referred to as AUS/FLUS.

\section{H I G G H L I G G H T S}

- Core needle biopsy (CNB) can significantly decrease the frequency of non-diagnostic findings.

- CNB results in an increased frequency of findings of architectural atypia and follicular neoplasm.

- The preference for CNB is related to the frequency of atypia of undetermined significance/follicular lesion of undetermined significance results.

- The complication rate did not differ between fine-needle aspiration and $\mathrm{CNB}$, but serious complications are possible in CNB.

\section{Data analysis}

A proportional meta-analysis was performed to compare the frequencies of diagnoses, and multiple comparisons were performed between six subgroups. The Bonferroni correction was applied to determine the $P$-values of inter-group differences. The proportional meta-analysis was performed using a comprehensive metaanalysis (Biostat, Englewood, NJ, USA). Forest plots were constructed using Excel (Microsoft Corp., Redmond,WA, USA).

\section{RESULTS}

\section{Articles published by Korean authors on FNA or CNB in thyroid diseases}

After removing duplicates, 965 records were retrieved from Embase. Screening of titles excluded 721 irrelevant records, leaving

Table 1. Number of papers on FNA or CNB in thyroid diseases published by authors from Korea

\begin{tabular}{|c|c|c|c|}
\hline Index & Institute & FNA & CNB \\
\hline 1 & Ajou University & 2 & 0 \\
\hline 2 & Asan Medical Center & 18 & 29 \\
\hline 3 & Busan Paik Hospital & 17 & 0 \\
\hline 4 & Catholic University & 10 & 3 \\
\hline 5 & Chung-Ang University & 1 & 1 \\
\hline 6 & Chungbuk National University & 1 & 0 \\
\hline 7 & Chungnam National University & 4 & 0 \\
\hline 8 & Dong-A University & 1 & 0 \\
\hline 9 & Ewha Womans University & 1 & 0 \\
\hline 10 & Gacheon University & 1 & 1 \\
\hline 11 & Yonsei University Gangnam Severance Hospital & 7 & 0 \\
\hline 12 & Gangneung Asan Hospital & 2 & 2 \\
\hline 13 & Gyeongsang National University & 2 & 0 \\
\hline 14 & Hallym University & 1 & 0 \\
\hline 15 & Human Medical Imaging & 5 & 3 \\
\hline 16 & Inha University & 2 & 0 \\
\hline 17 & Inje University & 1 & 0 \\
\hline 18 & Kangbuk Samsung Hospital & 1 & 0 \\
\hline 19 & Konkuk University & 7 & 0 \\
\hline 20 & Korea University & 7 & 0 \\
\hline 21 & Kyungpook National University & 2 & 1 \\
\hline 22 & Myongji Hospital & 1 & 0 \\
\hline 23 & National Cancer Center & 2 & 0 \\
\hline 24 & Pusan National University & 3 & 0 \\
\hline 25 & Samsung Medical Center & 20 & 4 \\
\hline 26 & Seoul National University Boramae Hospital & 2 & 0 \\
\hline 27 & Seoul National University Bundang Hospital & 6 & 4 \\
\hline 28 & Seoul National University Hospital & 8 & 2 \\
\hline 29 & Yonsei University Severance Hospital & 65 & 4 \\
\hline 30 & Soonchunhyang University & 1 & 0 \\
\hline 31 & Ulsan University Hospital & 1 & 0 \\
\hline 32 & Yeouido St. Mary's Hospital & 1 & 0 \\
\hline Total & & 204 & 54 \\
\hline
\end{tabular}

FNA, fine-needle aspiration; CNB, core needle biopsy. 
244 records for abstract or full-text review. Before further exclusion from the qualitative synthesis, the frequency of publications on FNA and CNB was analyzed by hospital (Table 1). In total, 204 articles on FNA and 54 on CNB were published by authors from 32 hospitals. Papers on CNB were published by authors from only 11 of those 32 hospitals (34.4\%), suggesting that specific hospitals favored CNB. After excluding 188 additional records, the meta-analysis finally included 56 records. The reasons for exclusion and the number of records included in the metaanalysis are described in Fig. 1.

\section{Comparison of CNB and repeated FNA in thyroid nodules with non-diagnostic or AUS/FLUS results on initial FNA}

Eleven studies reported biopsy results after initial non-diagnostic or AUS/FLUS results [1,13-22]. Of those papers, the study period of Yeon et al. [20] overlapped with that of another paper [13] published using data from the same hospital and was excluded.

\section{CNB and repeated FNA in nodules with non-diagnostic initial FNA findings}

Three papers $[13,16,17]$ compared CNB and repeated FNA of nodules with non-diagnostic initial FNA results, while one paper [21] reported only the results of repeated FNA. The study details are summarized in Table 2 . The proportional meta-analysis of the diagnoses for each criterion showed a significantly lower pooled proportion of non-diagnostic results for CNB than for FNA $(1.6 \%$ vs. $34.4 \%, P<0.001$ ) (Fig. $2 \mathrm{~A}$ ). The proportions of other diagnostic categories did not differ significantly between CNB and repeated FNA (Supplementary Fig. 1). Although the proportions

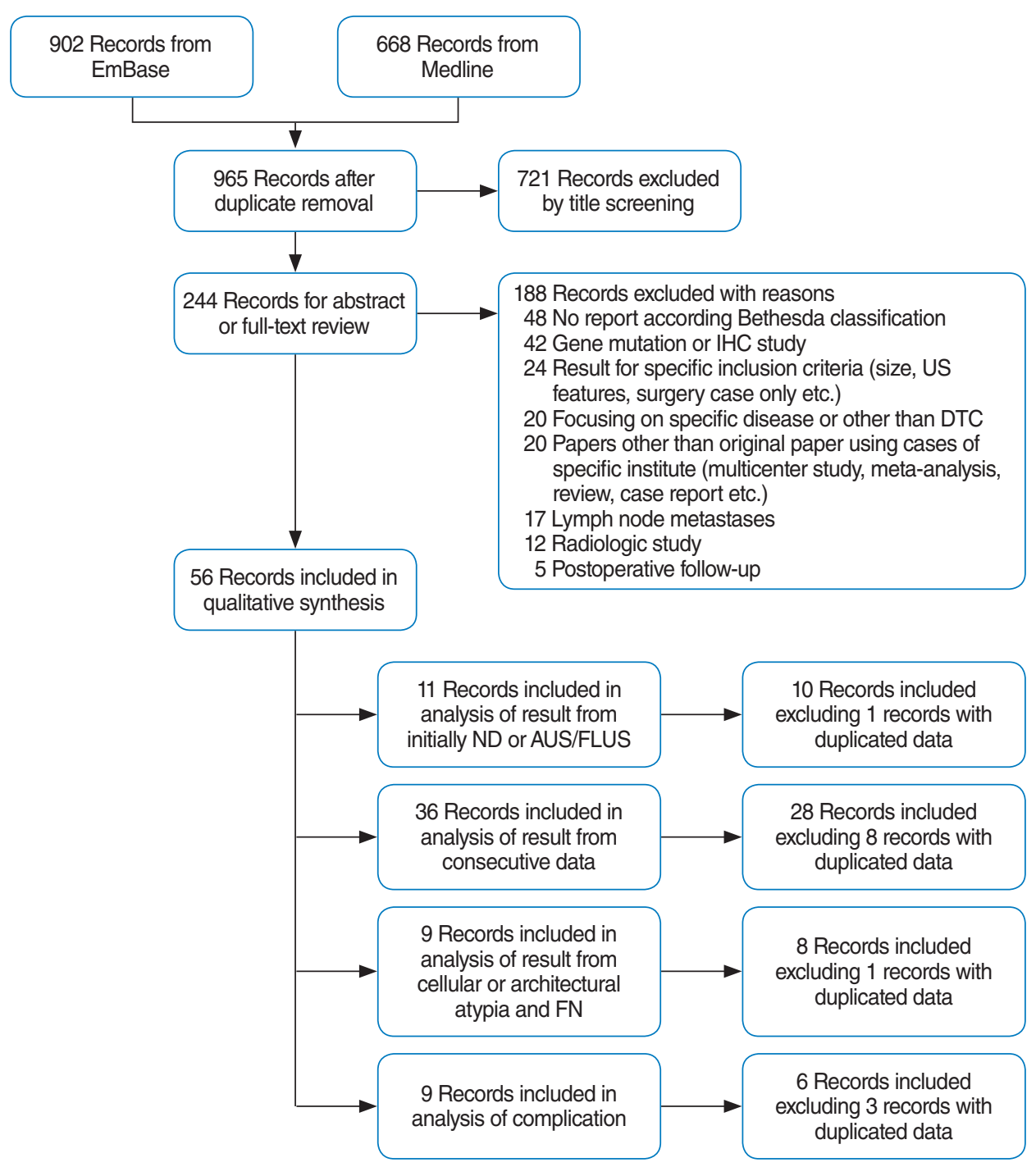

Fig. 1. Flow diagram illustrating the literature search protocol. IHC, immunohistochemistry; US, ultrasound; DTC, differentiated thyroid carcinoma; ND, non-diagnostic; AUS/FLUS, atypia of undetermined significance/follicular lesion of undetermined significance; FN, follicular neoplasm. 
of follicular neoplasm/suspicious for follicular neoplasm diagnoses (FN/SFN; pooled proportion: $5.8 \%$ in CNB and $1.1 \%$ in FNA, $P$-value before the Bonferroni correction $=0.021$ ) and malignancy (pooled proportion: $16.6 \%$ in $\mathrm{CNB}$ and $5.0 \%$ in FNA, $P$-value before the Bonferroni correction $=0.022$ ) were higher in CNB than those in FNA, the differences were not statistically significant after the Bonferroni correction.

\section{CNB and repeated FNA in nodules with AUS/FLUS findings on initial FNA}

Seven papers $[1,14,15,17-19,22]$ reported CNB or FNA results in nodules initially diagnosed as AUS/FLUS (Table 3). Among these seven papers, two reported only the results of FNA $[15,19]$. Others compared CNB and repeated FNA results and assessed the usefulness of CNB. However, Yoon et al. [22] concluded that despite the lower rates of inconclusive results from CNB than from repeated FNA, CNB did not decrease the rate of diagnostic surgery, reflecting a weakness of CNB.

The proportional meta-analysis showed significantly lower proportions of non-diagnostic findings on CNB than on FNA (pooled proportions: $3.0 \%$ vs. $11.8 \%, P=0.002$ ) (Fig. $2 \mathrm{~B}$ ). The proportion of AUS/FLUS findings on CNB was lower than that observed for repeated FNA (pooled proportions: $24.1 \%$ vs. $35.2 \%$ ) (Fig. 2C) but the difference was not statistically significant $(P=0.379)$ due to the wide variability in CNB. Meanwhile, the proportion of FN/SFN diagnoses was significantly higher for CNB than for repeated FNA ( $8.0 \%$ vs. $1.7 \%, P=0.017$ ) (Fig. 2D). The proportions of other diagnostic categories did not significantly differ between CNB and repeated FNA (Supplementary Fig. 2).

\section{Proportions of diagnoses made using CNB or FNA in consecutive patients}

Among the 56 studies included in the qualitative analysis, 36 included data on the proportions of diagnoses following the TBSRTC or equivalent criteria [23-57]. Eight papers [24,36,39,40, $42,44,51,55]$ were excluded because their study periods overlapped with those of other papers reporting data from the same hospital; thus, the analysis included 28 papers. Five papers reported diagnostic findings for both CNB and FNA [30,33,43,54, 56], while four papers $[23,26,27,31]$ reported CNB results only.

Table 2. Comparison of repeated FNA and CNB in thyroid nodules with non-diagnostic results on initial FNA

\begin{tabular}{|c|c|c|c|c|}
\hline Study & Institute & Study period & Included case & Main outcome \\
\hline $\begin{array}{l}\text { Choi et al. } \\
\qquad(2014)[13]\end{array}$ & $\begin{array}{l}\text { Asan Medical } \\
\text { Center }\end{array}$ & 2008.10-2011.12 & $\begin{array}{l}360 \text { Consecutive nodules; } \\
180 \text { FNA and } 180 \text { CNB }\end{array}$ & $\begin{array}{l}\text { Non-diagnostic results: } 1.1 \% \text { CNB vs. } 40 \% \text { FNA }(P<0.001) \\
\text { Inconclusive results: } 7.2 \% \text { CNB vs. } 72 \% \text { FNA }(P<0.001)\end{array}$ \\
\hline $\begin{array}{l}\text { Lee et al. } \\
\qquad(2014)[16]\end{array}$ & $\begin{array}{l}\text { Catholic } \\
\text { University }\end{array}$ & $2008.10-2012.8$ & $\begin{array}{l}389 \text { FNA, } 125 \text { CNB, } \\
\text { retrospective }\end{array}$ & Non-diagnostic results: $2.4 \%$ CNB vs. 33.2\% FNA $(P<0.001)$ \\
\hline $\begin{array}{l}\text { Na et al. } \\
\text { (2012) [17] }\end{array}$ & $\begin{array}{l}\text { Human Medical } \\
\text { Imaging }\end{array}$ & 2009.2-2010.1 & $\begin{array}{l}64 \text { Nodules with simultaneous } \\
\text { FNA and CNB, prospective }\end{array}$ & $\begin{array}{l}\text { Non-diagnostic results: } 1.6 \% \text { CNB vs. } 28.1 \% \text { FNA }(P<0.001) \\
\text { Inconclusive results: } 12.5 \% \text { CNB vs. } 45.3 \% \text { FNA }(P<0.001)\end{array}$ \\
\hline $\begin{array}{l}\text { Yoon et al. } \\
\text { (2018) [21] }\end{array}$ & $\begin{array}{l}\text { Severance } \\
\text { Hospital }\end{array}$ & $2010.1-2013.1$ & $\begin{array}{l}175 \text { Repeated FNA for } 322 \\
\text { nodules }(\geq 1 \mathrm{~cm})\end{array}$ & $\begin{array}{l}\text { Interval for repeated biopsy in nodules with initially } \\
\text { non-diagnostic results: } 6 \text { months will be safe }\end{array}$ \\
\hline
\end{tabular}

FNA, fine-needle aspiration; CNB, core needle biopsy.

Result of repeated FNA and CNB in Nodules with Non-Diagnostic result in 1st FNA

Study

event Total \% Diagnosis CI lower CI upper \% weight

Rate \%

Random effects (DerSimonian-Laird)

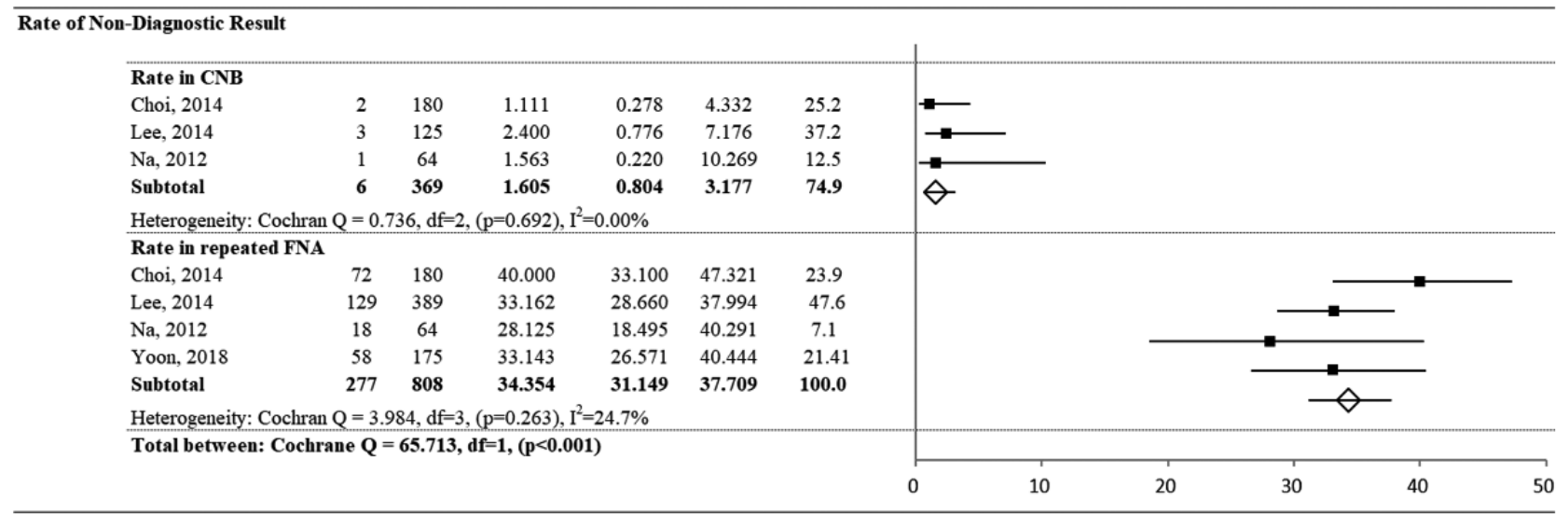

Fig. 2. Forest plot of the proportional analysis of diagnostic categories between core needle biopsy (CNB) and fine-needle aspiration (FNA) performed in nodules initially classified as non-diagnostic or atypia of undetermined significance/follicular lesion of undetermined significance (AUS/FLUS). (A) Proportion of non-diagnostic results in nodules with non-diagnostic results from initial FNA.

(Continued to the next page) 
Result of repeated FNA and CNB in Nodules with AUS/FLUS result in 1st FNA

event Total \% diagnosis CI lower $\mathrm{CI}$ upper \% weight

Rate \%

Random effects (DerSimonian-Laird)

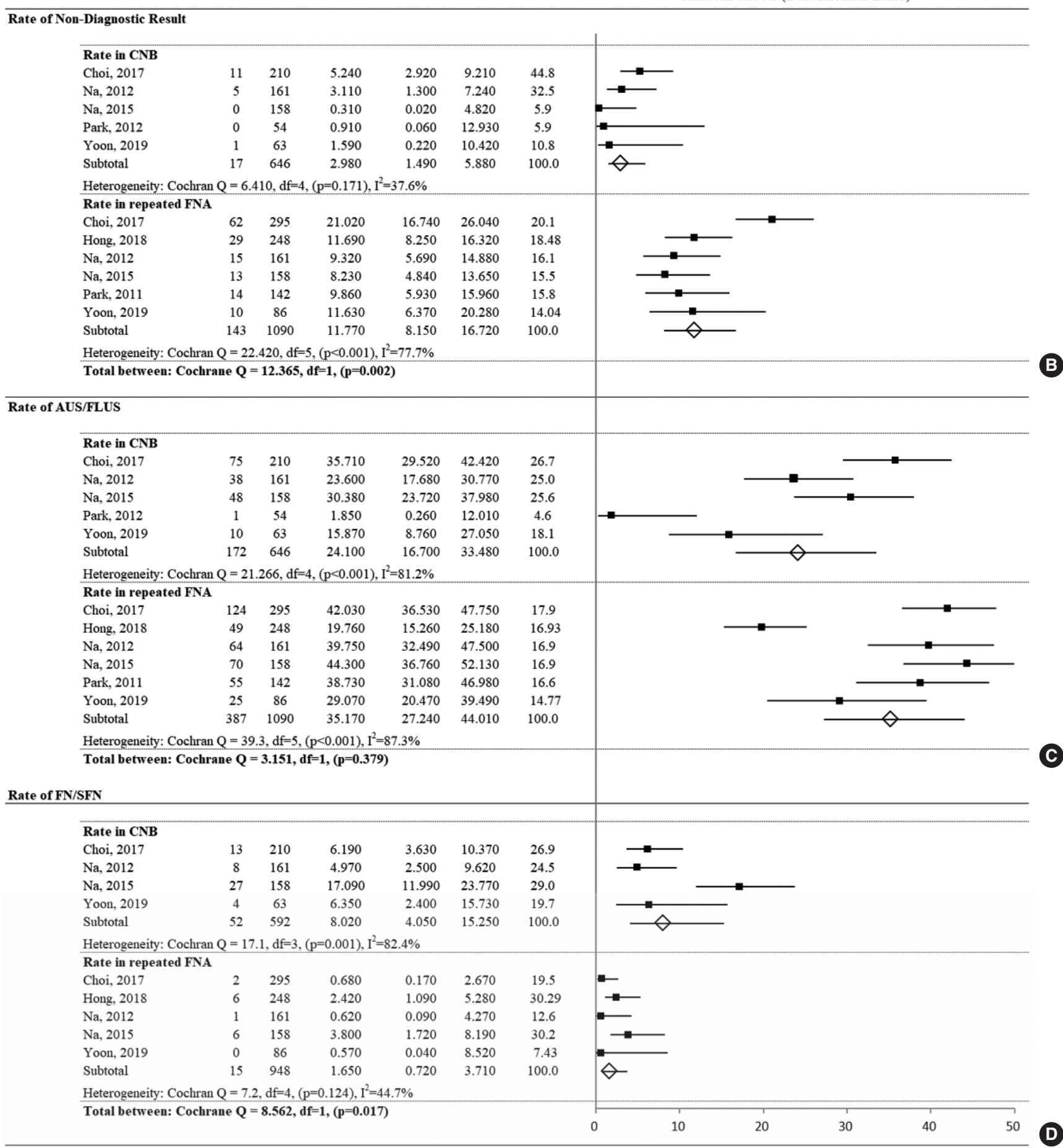

Fig. 2. (Continued) Proportion of diagnoses in nodules with AUS/FLUS results from initial FNA: non-diagnostic result (B), AUS/FLUS (C), and follicular neoplasm/suspicious of follicular neoplasm (FN/SFN; D). Cl, confidence interval.

The other papers reported FNA data. Table 4 presents a detailed summary of each paper.
Differences in the proportions of diagnoses on consecutive FNA between hospitals favoring or not favoring CNB

Twenty-four papers reporting the proportions of diagnoses made 
Table 3. Comparison of repeated FNA and CNB in thyroid nodules with AUS/FLUS results on initial FNA

\begin{tabular}{|c|c|c|c|c|}
\hline Study & Institute & Study period & Included case & Main outcome \\
\hline $\begin{array}{l}\text { Choi et al. } \\
\text { (2017) [14] }\end{array}$ & Asan Medical Center & 2008-2013.7 & $\begin{array}{l}505 \text { Consecutive nodules with } 295 \\
\text { FNA and } 210 \text { CNB, retrospective }\end{array}$ & $\begin{array}{l}\text { Rate of inconclusive results (non-diagnostic or AUS/ } \\
\text { FLUS): } 40.9 \% \text { in CNB vs. } 63 \% \text { in FNA }(P<0.001)\end{array}$ \\
\hline $\begin{array}{l}\text { Hong et al. } \\
\text { (2018) [15] }\end{array}$ & Ewha Womans University & $2011.1-2014.12$ & $\begin{array}{l}\text { Among } 687 \text { nodules with AUS/ } \\
\text { FLUS, repeated FNA in } 248\end{array}$ & $\begin{array}{l}\text { Malignancy risk according to ultrasound findings } \\
\text { and clinical features }\end{array}$ \\
\hline $\begin{array}{l}\text { Na et al. } \\
(2012)[17]\end{array}$ & Human Medical Imaging & 2009.2-2010.1 & $\begin{array}{l}161 \text { AUS/FLUS; simultaneous } \\
\text { repeated FNA and CNB, } \\
\text { prospective }\end{array}$ & $\begin{array}{l}\text { AUS/FLUS results: } 23.6 \% \text { in CNB vs. } 39.8 \% \text { in FNA } \\
(P<0.001) \\
\text { Inconclusive results: } 26.7 \% \text { in CNB vs. } 49.1 \% \text { in } \\
\text { FNA }(P<0.001)\end{array}$ \\
\hline $\begin{array}{l}\text { Na et al. } \\
\text { (2015) [18] }\end{array}$ & Human Medical Imaging & $2010.2-2013.7$ & $\begin{array}{l}158 \text { Consecutive AUS/FLUS } \\
\text { nodules }(\geq 1 \mathrm{~cm}) \text { with } \\
\text { simultaneous FNA and CNB }\end{array}$ & $\begin{array}{l}\text { Comparison of subcategory of AUS/FLUS; nuclear } \\
\text { atypia vs. follicular lesions with other atypia; CNB } \\
\text { is more helpful for surgical decision-making than } \\
\text { FNA }\end{array}$ \\
\hline $\begin{array}{l}\text { Park et al. } \\
\text { (2011) [1] }\end{array}$ & $\begin{array}{l}\text { Seoul National University } \\
\text { Bundang Hospital }\end{array}$ & 2005.2-2009.7 & $\begin{array}{l}142 \text { FNA and } 54 \text { CNB, } \\
\text { retrospective }\end{array}$ & $\begin{array}{l}\text { Non-diagnostic (unsatisfactory or indeterminate) } \\
\text { rate was } 1.8 \% \text { in CNB and } 48.6 \% \text { in FNA }\end{array}$ \\
\hline $\begin{array}{l}\text { Park et al. } \\
\text { (2015) [19] }\end{array}$ & Severance Hospital & $2010.1-2013.1$ & 236 Repeated FNA & $\begin{array}{l}\text { Malignancy rate in nodules with two consecutive } \\
\text { results of AUS/FLUS }\end{array}$ \\
\hline $\begin{array}{l}\text { Yoon et al. } \\
\text { (2019) [22] }\end{array}$ & Severance Hospital & 2013.5-2015.7 & $\begin{array}{l}149 \text { Nodules with } 86 \text { FNA and } 63 \\
\text { CNB }\end{array}$ & $\begin{array}{l}\text { Inconclusive results: } 33.7 \% \text { in FNA vs } 11.1 \% \text { in CNB } \\
(P=0.003) \text {. Diagnostic surgery rate was the same } \\
\text { in both groups - CNB did not decrease the } \\
\text { frequency of diagnostic lobectomy. }\end{array}$ \\
\hline
\end{tabular}

FNA, fine-needle aspiration; CNB, core needle biopsy; AUS/FLUS, atypia of undetermined significance/follicular lesion of undetermined significance.

using FNA published from 14 hospitals were included. Seven of these hospitals also published data about $\mathrm{CNB}$ and reported its advantages over FNA; these hospitals were categorized as favoring CNB. One hospital focused on the weaknesses or disadvantages of $\mathrm{CNB}$ in four papers [22,43,58,59]; despite publishing papers on $\mathrm{CNB}$, we categorized this hospital as not favoring CNB. Head and neck surgeons working at five other hospitals without a paper on CNB were contacted to obtain information on their use of $\mathrm{CNB}$, and they confirmed that they rarely used CNB in clinical settings. Therefore, data from 14 papers [30,32$35,41,46,48-50,52,54,56,57]$ published by authors from eight hospitals favoring $\mathrm{CNB}$ were compared to data from 10 papers $[25,28,29,37,38,43,45,47,53,60]$ published by authors from six hospitals that did not favor CNB to identify differences in the proportions of diagnoses according to the TBSRTC. Fig. 3A shows the differences in the pooled estimates obtained by applying the TBSRTC criteria between hospitals that did or did not favor CNB. The most significant between-group difference was the higher frequency of AUS/FLUS findings at hospitals favoring CNB than at hospitals not favoring CNB (12.3\% vs. $5.1 \%$, $P<0.001)$. In addition, benign diagnoses were more frequent at hospitals not favoring CNB than at those favoring CNB $(60.5 \%$ vs. $51.3 \%, P=0.028)$. The proportions of other diagnoses did not significantly differ between these two groups of hospitals. Forest plots for each diagnosis are shown in Supplementary Fig. 3.

\section{Differences in the proportions of diagnoses between consecutive FNA and CNB}

Consecutive data on FNA (24 papers) and CNB (nine papers) were compared in a proportional meta-analysis. The frequency of the proportions of each TBSRTC category differed significantly between FNA and CNB (Fig. 3B). Non-diagnostic, benign, and suspicious for malignancy findings were significantly more common on FNA than on CNB. However, CNB had significantly higher proportions of AUS/FLUS, FN/SFN, and malignancy diagnoses than FNA. The forest plots for the proportional analysis are presented in Supplementary Fig. 4.

\section{Proportional differences in AUS/FLUS diagnoses between FNA and CNB}

AUS/FLUS includes various conditions for which cellular atypia/ architectural atypia is a representative subcategory. To understand the reasons for the higher frequency of AUS/FLUS diagnoses on $\mathrm{CNB}$, we analyzed proportional differences in subcategories of diagnoses and compared the malignancy risks of cellular/architectural atypia and FN/SFN diagnosed by FNA or CNB. Eight publications included data on the AUS/FLUS subcategory or the role of CNB in FN/SFN [18,24,30,34,61-65]. Park et al. [63] was excluded from the present meta-analysis due to overlap of the study period with other papers analyzing data from the same hospital; thus, the analysis included eight papers (Table 5).

\section{Cellular atypia versus architectural atypia}

This analysis included seven papers. Ahn et al. [24] included both FNA and CNB results, Chung et al. [30] reported CNB results, and the others included FNA data $[18,34,61,62,64]$. Architectural atypia comprised approximately $71.9 \%$ of AUS/FLUS cases diagnosed by $\mathrm{CNB}$; in contrast, cellular atypia comprised a pooled rate of $70.1 \%$ of AUS/FLUS cases diagnosed by FNA (Fig. 4A). 


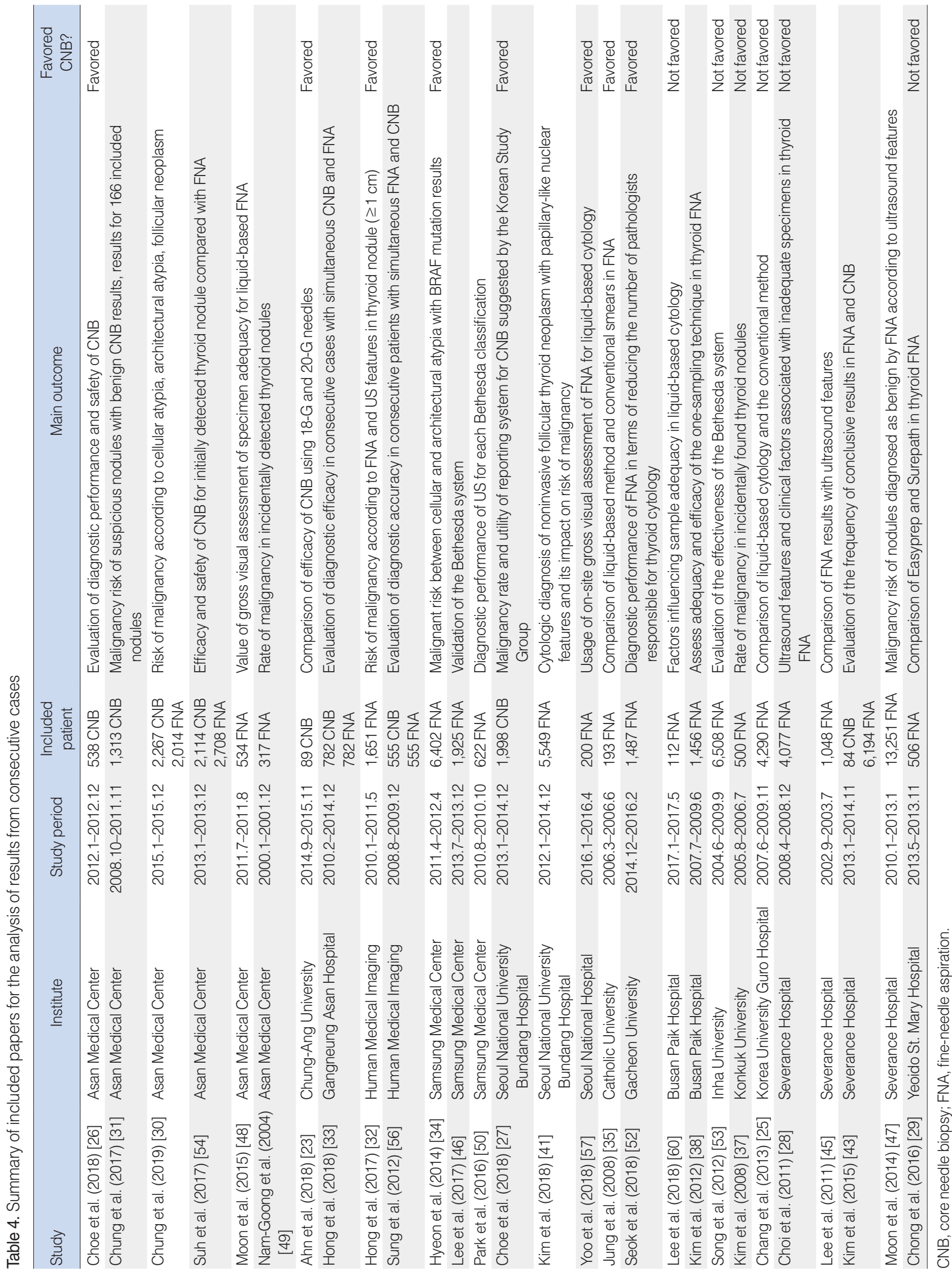




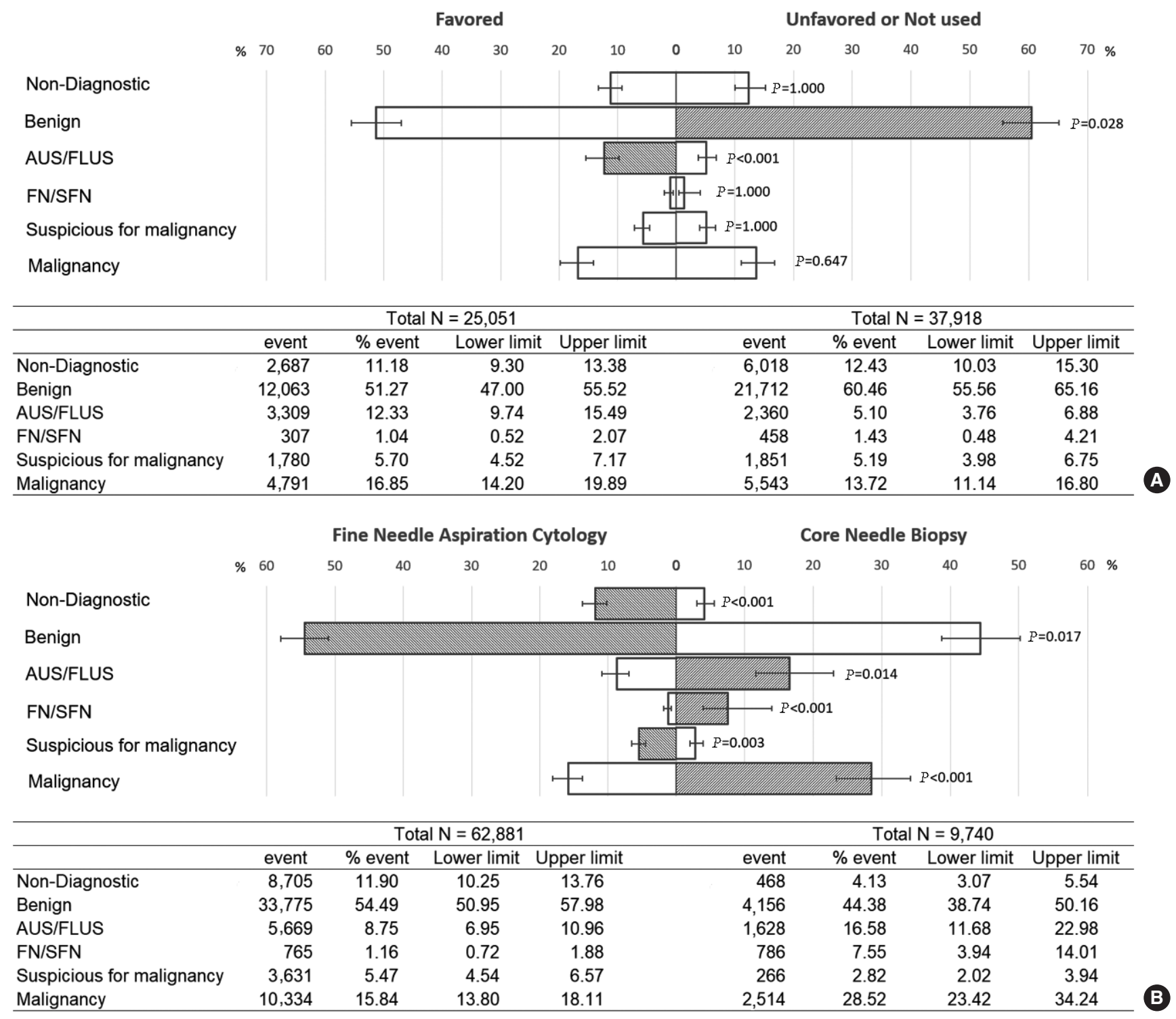

Fig. 3. Comparison of pooled estimates of the proportions of diagnoses for each Bethesda System for Reporting Thyroid Cytopathology (TBSRTC) category from consecutive data. The hatched bar indicates a statistically significant increase in diagnostic frequency. (A) Comparison of fine-needle aspiration (FNA) results between hospitals favoring core needle biopsy (CNB) or FNA. (B) Comparison of CNB and FNA results. AUS/FLUS, atypia of undetermined significance/follicular lesion of undetermined significance; FN/SFN, follicular neoplasm/suspicious for follicular neoplasm.

\section{Malignancy risk of cellular or architectural atypia and FN/SFN diagnosed by CNB or FNA}

The malignancy rate of cellular or architectural atypia was analyzed based on six papers $[24,30,34,61,62,64]$. The pooled risk of malignancy in nodules with both cellular and architectural atypia did not differ significantly depending on whether they were diagnosed using CNB or FNA. The pooled malignancy risk of cellular atypia in CNB and FNA was $27.0 \%$ and $32.8 \%$, respectively (Fig. 4B) and $12.7 \%$ and $9.6 \%$ for architectural atypia, respectively (Fig. 4C). Three papers reported the pooled risk of malignancy of FN/SFN [24,30,65], also without significant differences (34.2\% for CNB and $28.5 \%$ for FNA) (Fig. 4D).

\section{Complications of CNB and FNA}

Nine papers [23,26,36,54,55,58,66-68] reported complications after CNB or FNA. Three papers $[26,55,67]$ included cases overlapping with other papers from the same institution; thus, the final analysis included six papers. While the proportional metaanalysis showed that the pooled complication rate of CNB $(1.5 \%)$ was higher than that of FNA $(0.7 \%)$, the difference was not statistically significant $(P=0.351)$ (Supplementary Fig. 5). Table 6 lists the complications observed after FNA and CNB. Hematoma was the only reported complication of FNA. However, in patients who underwent $\mathrm{CNB}$, although very rare, more serious complications were reported, including pseudoaneurysm 
Celluar atypia vs. Architectural atypia in Diagnosis of AUS/FLUS

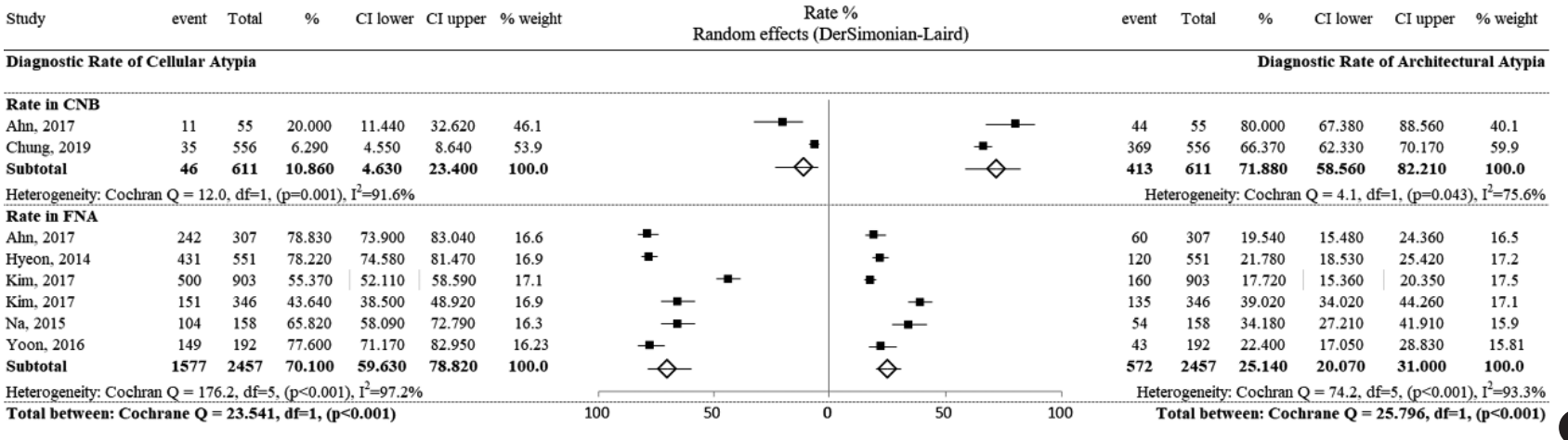

Rate of Malignancy in Cellular Atypia/Architectural Atypia/Follicular Neoplasm

Study event Total \% Malignancy CI lower CI upper \%weight

Rate \%

Random effects (DerSimonian-Laird)

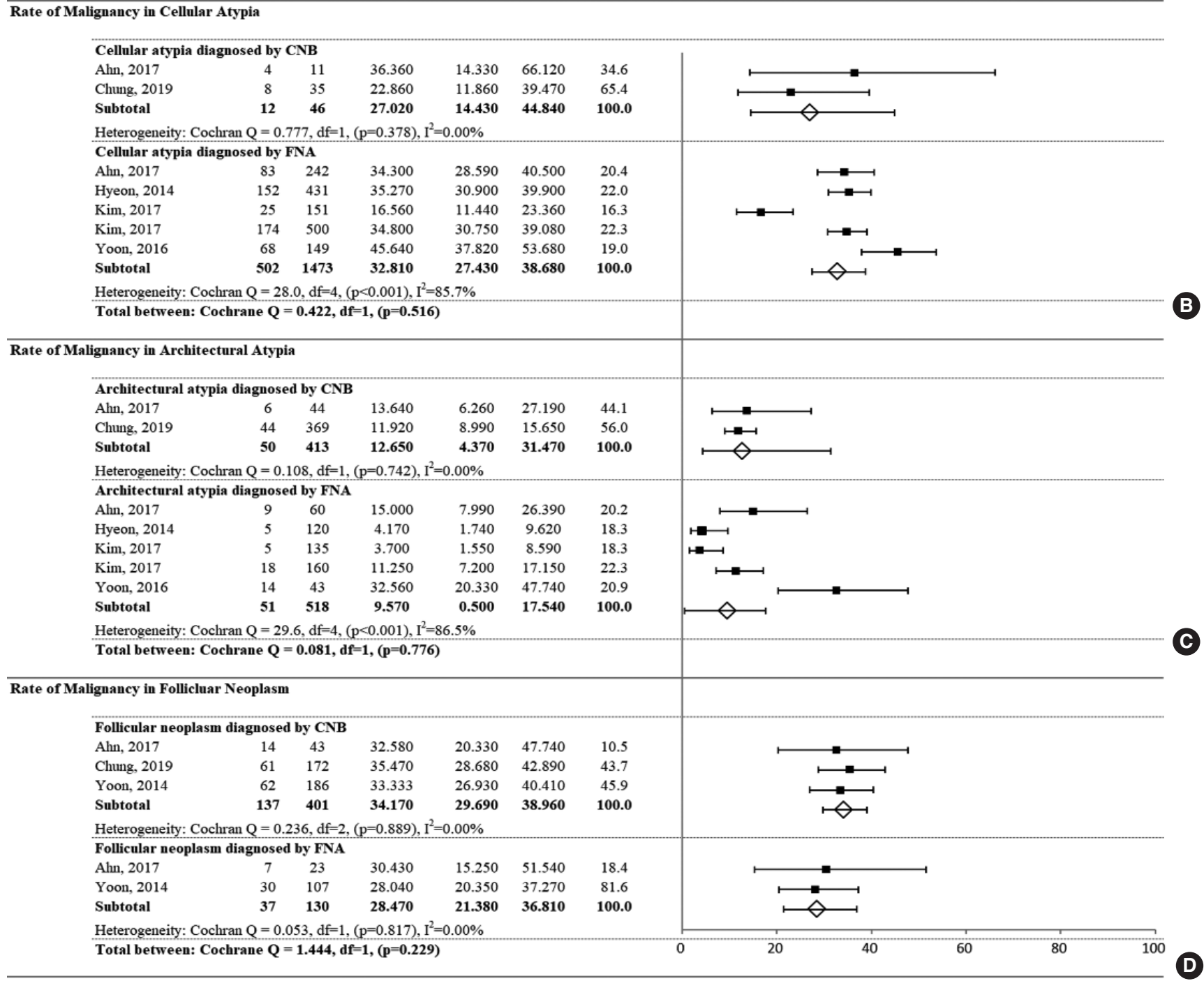

Fig. 4. Forest plot of the proportional analysis. (A) Diagnostic frequency of cellular and architectural atypia in atypia of undetermined significance/follicular lesion of undetermined significance (AUS/FLUS) diagnosed by core needle biopsy (CNB) and fine-needle aspiration (FNA) cytology. (B) Comparison of risk of malignancy diagnosed by CNB and FNA: cellular atypia (B), architectural atypia (C), and follicular neoplasm (D). Cl, confidence interval. 
Table 5. Comparison of subcategories of AUS/FLUS and the malignancy rate in AUS/FLUS and FN

\begin{tabular}{|c|c|c|c|c|}
\hline Study & Institute & Study period & Included case & Main outcome \\
\hline $\begin{array}{l}\text { Ahn et al. } \\
\text { (2017) [24] }\end{array}$ & $\begin{array}{l}\text { Seoul National University } \\
\text { Bundang Hospital }\end{array}$ & 2004.10-2014.7 & $\begin{array}{l}\text { 2,131 Consecutive FNA and } 275 \text { CNB; } \\
307 \text { AUS/FLUS in FNA and } 55 \text { AUS/ } \\
\text { FLUS in CNB, } 21 \text { FN in FNA, } 41 \text { FN } \\
\text { in CNB }\end{array}$ & $\begin{array}{l}\text { Consecutive comparison of results between FNA } \\
\text { and CNB; frequency of cellular and } \\
\text { architectural atypia and its malignancy risk, } \\
\text { malignancy risk of FN }\end{array}$ \\
\hline $\begin{array}{l}\text { Chung et al. } \\
\text { (2019) [30] }\end{array}$ & Asan Medical Center & 2015.1-2015.12 & $\begin{array}{l}556 \text { AUS/FLUS obtained from CNB; } \\
\text { classified as architectural, cytologic, } \\
\text { both, oncocytic, } 172 \text { SFN included }\end{array}$ & $\begin{array}{l}\text { Architectural atypia in } 66.4 \% \text {, cytologic atypia in } \\
6.3 \% \text {, risk of malignancy was } 22.9 \%-88.9 \% \text { in } \\
\text { cytologic atypia, } 11.9 \%-40.0 \% \text { in architectural } \\
\text { atypia. The malignancy rate of SFN was } \\
\text { evaluated. }\end{array}$ \\
\hline $\begin{array}{l}\text { Hyeon et al. } \\
\text { (2014) [34] }\end{array}$ & Samsung Medical Center & r 2011.4-2012.4 & $\begin{array}{l}551 \text { AUS/FLUS from 6,402 FNAs; } 431 \\
\text { AUS, } 120 \text { FLUS }\end{array}$ & $\begin{array}{l}\text { Malignancy risk and frequency of BRAF } \\
\text { mutation in each subcategory }\end{array}$ \\
\hline $\begin{array}{l}\text { Kim et al. } \\
\text { (2017) [61] }\end{array}$ & $\begin{array}{l}\text { Seoul National University } \\
\text { Bundang Hospital }\end{array}$ & 2010.1-2014.8 & $\begin{array}{l}903 \text { AUS/FLUS from FNA; } 500 \text { cellular } \\
\text { atypia, } 160 \text { architectural atypia }\end{array}$ & $\begin{array}{l}\text { Malignancy risk; } 48.2 \% \text { in cellular atypia, } 14.2 \% \\
\text { in architectural atypia }\end{array}$ \\
\hline $\begin{array}{l}\text { Kim et al. } \\
\text { (2017) [62] }\end{array}$ & Asan Medical Center & 2012.1-2012.12 & $\begin{array}{l}94 \text { AUS/FLUS from FNA; } \\
\text { subcategorized as nuclear, } \\
\text { architectural, oncocytic, or both }\end{array}$ & Higher malignancy rate in nuclear atypia (65.8\%) \\
\hline $\begin{array}{l}\text { Na et al. } \\
\text { (2015) [18] }\end{array}$ & Human Medical Imaging & 2010.2-2013.6 & $\begin{array}{l}158 \text { AUS/FLUS from FNA, nuclear } \\
\text { atypia vs. follicular lesions with other } \\
\text { atypia }\end{array}$ & $\begin{array}{l}\text { CNB showed higher proportions of benign and } \\
\text { FN diagnoses, especially in follicular lesions } \\
\text { with other atypia }\end{array}$ \\
\hline $\begin{array}{l}\text { Yoon et al. } \\
\text { (2016) [64] }\end{array}$ & Severance Hospital & $2011.7-2013.1$ & $\begin{array}{l}192 \text { AUS/FLUS from FNA, } 149 \text { AUS vs. } \\
43 \text { FLUS }\end{array}$ & Malignancy rate according to the TIRADS \\
\hline $\begin{array}{l}\text { Yoon et al. } \\
\text { (2014) [65] }\end{array}$ & Asan Medical Center & 2008.10-2013.12 & $\begin{array}{l}107 \text { FN patient from } 231 \text { FNA, } 107 \text { FN } \\
\text { from } 186 \text { CNB performed surgery }\end{array}$ & $\begin{array}{l}\text { Among patients with surgery, non-neoplasm was } \\
30.8 \% \text { in FNA, } 4.7 \% \text { in CNB, higher rate of } \\
\text { malignancy in CNB group ( } 57.9 \% \text { vs. } 28 \% \text { ) }\end{array}$ \\
\hline
\end{tabular}

AUS/FLUS, atypia of undetermined significance/follicular lesion of undetermined significance; FN, follicular neoplasm; FNA, fine-needle aspiration; CNB, core needle biopsy; SFN, suspicious for follicular neoplasm; TIRADS, thyroid Imaging Reporting and Data System.

Table 6. Complications following CNB or FNA

\begin{tabular}{|c|c|c|c|c|}
\hline Study & Institute & Study period & Included case & Main outcome \\
\hline Ahn et al. (2018) [23] & $\begin{array}{l}\text { Chung-Ang University } \\
\text { Hospital }\end{array}$ & 2014.9-2015.11 & $\begin{array}{l}\text { 20G CNB; } 81 \text { cases } \\
18 G \text { CNB; } 86 \text { cases }\end{array}$ & $\begin{array}{l}\text { 20G CNB: } 2 \text { hematomas } \\
\text { 18G CNB: } 2 \text { hematomas, } 1 \text { pseudoaneurysm }\end{array}$ \\
\hline Chae et al. (2017) [58] & Severance Hospital & 2012.1-2012.12 & 5,121 FNA vs. 183 CNB & 43 Hematomas in FNA, 9 hematomas in CNB \\
\hline Ha et al. (2017) [66] & Asan Medical Center & 2008.1-2013.3 & $6,687 \mathrm{CNB}$ & $\begin{array}{l}53 \text { Complications: } \\
2 \text { massive hematomas, } 1 \text { pseudoaneurysm, } \\
1 \text { prolonged voice change } \\
42 \text { small to moderate hematomas, } 2 \text { carotid injuries, } \\
3 \text { cases of transient voice change, } 1 \text { tracheal } \\
\text { puncture, } 1 \text { dysphagia, } 12 \text { cases of edema, } 3 \text { cases } \\
\text { of vertebral puncture, } 1 \text { vasovagal reaction }\end{array}$ \\
\hline Kim et al. (2019) [68] & $\begin{array}{l}\text { Seoul National University } \\
\text { Bundang Hospital }\end{array}$ & 2015.7-2015.12 & 87 FNA vs. 80 CNB & 3 Hematomas in FNA, 2 hematomas in CNB \\
\hline Jung et al. (2018) [36] & Busan Paik Hospital & 2017.1-2017.4 & $\begin{array}{l}\text { 21G FNA; } 38 \text { cases } \\
\text { 23G FNA: } 50 \text { cases }\end{array}$ & 1 Hematoma in 21G FNA \\
\hline Suh et al. (2017) [54] & Asan Medical Center & 2013.1-2013.12 & 2,708 FNA vs. 2,114 CNB & 2 Hematomas in FNA, 7 hematomas in CNB \\
\hline
\end{tabular}

CNB, core needle biopsy; FNA, fine-needle aspiration.

due to carotid or tracheal injuries.

\section{DISCUSSION}

The 2015 guideline of the American Thyroid Association briefly noted papers on the usefulness of CNB for the description of non-diagnostic or AUS/FLUS results [69]. Many papers have re- ported the results of CNB in thyroid nodules; a PubMed search with the term 'core needle biopsy[ti] thyroid' resulted in 117 records, of which 68 (58.1\%) were from Korea. However, even with the high interest in CNB in Korea, perceptions of CNB vary among hospitals. Some hospitals apply CNB as an important testing method, while others think it is unnecessary. This systemic review evaluated how hospitals in Korea viewed CNB for thyroid nodules. As shown in Table 1, authors from many hospitals have 
published studies on FNA, while researchers from only one-third of hospitals (34.4\%) have published studies on CNB, illustrating the differences in perceptions of CNB in Korea.

\section{Advantages of CNB in nodules initially classified as non-diagnostic or AUS/FLUS on FNA}

The use of CNB as a secondary test in nodules initially classified as non-diagnostic or AUS/FLUS by FNA is a relatively commonly accepted indication. In addition, meta-analyses have shown that CNB of nodules with initial non-diagnostic or inconclusive results by FNA yields significantly fewer non-diagnostic or inconclusive findings than obtained using FNA $[6,7,9]$. In the present meta-analysis, CNB showed significantly fewer non-diagnostic findings than repeated FNA in nodules with non-diagnostic findings on initial FNA ( $1.6 \%$ vs. $34.4 \%, P<0.001)$, with homogeneous results across papers. A comparison of $\mathrm{CNB}$ and repeated FNA in nodules initially diagnosed as AUS/FLUS using FNA showed complex results. In this scenario, significantly fewer non-diagnostic results were observed for CNB than for FNA, and the results of CNB were homogeneous. However, the proportion of AUS/FLUS diagnoses did not significantly differ between CNB and repeated FNA, although the pooled estimate of AUS/FLUS diagnoses was lower in CNB than in repeated FNA $(24.1 \%$ vs. $35.2 \%)$. The forest plot showed extensive heterogeneity between studies, which explains the lack of statistical significance. Simultaneously, the proportion of FN/SFN diagnoses was significantly higher on CNB. While previous meta-analyses assessed CNB and FNA after initial AUS/FLUS findings [6,8,9], they focused on the proportions of inconclusive findings, including non-diagnostic findings and AUS/FLUS combined, and showed a decreased frequency of inconclusive findings for CNB. Therefore, whether we should really expect a lower likelihood of repeated diagnosis of AUS/FLUS by selecting CNB rather than FNA is unclear, and the higher frequency of FN/SFN diagnoses obtained by CNB may result in an increased diagnostic surgery rates, as described by Yoon et al. [22]. Therefore, while CNB resulted in significantly fewer non-diagnostic results in nodules with initially non-diagnostic or AUS/FLUS results, its effects on decreasing the frequency of AUS/FLUS findings are unclear.

\section{Factors related to differences in CNB preferences between hospitals}

Favoring $\mathrm{CNB}$ means using $\mathrm{CNB}$ as often as necessary, but not as a primary test. In contrast, not favoring CNB means that there is little use of CNB in clinical settings, which was confirmed by clinicians at each hospital. The reason for including only Korean papers was to confirm each hospital's preference for CNB by personal contact with head and neck surgeons working at the hospital. A proportional analysis was performed to investigate differences in diagnoses made using the TBSRTC classification across hospitals. Although there was considerable heterogeneity between studies, significantly higher proportions of AUS/FLUS diagnoses were observed in papers published by authors from hospitals favoring CNB than in papers published by authors from other hospitals $(12.3 \%$ vs. $5.1 \%)$. Therefore, we carefully suggest that differences in the patterns of pathological diagnoses may influence the preference for $\mathrm{CNB}$ and that the increased rate of inconclusive results from frequent AUS/FLUS findings may contribute to favoring CNB. A meta-analysis by Suh et al. in 2016 [8] compared the sensitivity of FNA between studies originating within and outside of Asia, and reported significantly higher sensitivity outside of Asia than within Asia ( $85 \%$ vs. $64 \%$ ). Considering that nine out of the 10 Asian papers cited in their paper were by Korean authors, this finding can be interpreted that the sensitivity of FNA performed in Korea is inferior to that of FNA performed in the West. The reason for this difference in sensitivity might be due to differences in the mindset of patients undergoing surgery. In Korea, patients often do not understand why surgery was performed if they hear that the nodule was not cancer after surgery. Therefore, diagnoses may be more conservative than suggested by TBSRTC. The risk of malignancy suggested by TBSRTC in AUS/FLUS, suspicious for malignancy, and malignant nodules is $5 \%-15 \%, 60 \%-75 \%$, and $97 \%-99 \%$, respectively [70]. However, the corresponding risks of malignancy are much higher in Korea; for instance, the risk of malignancy of AUS/FLUS and suspicious for malignancy nodules is approximately $30 \%$ and more than $90 \%$, respectively, according to our unpublished data. Therefore, many nodules that could be diagnosed as suspicious for malignancy according to TBSRTC may be diagnosed as AUS/FLUS in Korea, which may lower the sensitivity of FNA. Moreover, the frequency of non-diagnostic results on CNB was higher in papers outside of Asia. This finding may also explain the relative lack of interest in CNB in Western countries.

\section{Comparison of CNB and FNA based on results from consecutive cases: expectations from first-line CNB}

The results of consecutive cases in which CNB and FNA were performed were compared to estimate how the proportional frequency of diagnoses would be affected by using CNB as the first-line modality. The proportions of diagnoses for all categories differed significantly between CNB and FNA even after Bonferroni correction of the $P$-value. An important point is that the patient population is not the same for CNB and FNA. FNA may be frequently performed in cystic nodules to remove fluid, while CNB may be preferred in solid nodules. This difference should be considered when interpreting these results. Therefore, benign and malignant diagnoses are more frequent for FNA and CNB, respectively. Apart from these two diagnostic results, the frequencies of inconclusive findings also differed. CNB showed significantly fewer non-diagnostic findings, an observation consistent with those for $\mathrm{CNB}$ performed in secondary biopsy procedures. Moreover, suspicion for malignancy was less frequently reported for CNB. However, AUS/FLUS and FN/SFN were diagnosed sig- 
nificantly more frequently on CNB than on FNA. Therefore, the rates of inconclusive findings (non-diagnostic and AUS/FLUS) were nearly the same between CNB and FNA (20.7\% for both). However, a diagnosis of FN/SFN also results in diagnostic surgery and is sometimes considered to be an inconclusive finding. Therefore, if FN/SFN is included, the proportion of inconclusive results was higher for CNB than for FNA ( $28.3 \%$ vs. $21.8 \%)$. Based on these results, it may be difficult to recommend the generalized use of CNB in thyroid nodules if the purpose is to decrease the frequency of inconclusive findings. Another metaanalysis comparing the efficacy of CNB and FNA for diagnosing malignancy also showed no significant difference between the two modalities $[2,4]$.

\section{Increased frequency of AUS/FLUS on CNB due to increased diagnoses of architectural atypia}

There is continuing interest regarding differences in the risk of malignancy between subcategories of AUS/FLUS. Authors at our institution also published a meta-analysis showing different risks of malignancy between cellular and architectural atypia [71]. Many researchers have suggested that cellular and architectural atypia should be classified separately in TBSRTC [72], and the CNB diagnostic criteria proposed by the Korean Endocrine Pathology Thyroid Core Needle Biopsy Study Group are divided into IIIA (indeterminate follicular lesion with nuclear atypia) and IIIB (indeterminate follicular lesion with architectural atypia) accordingly. Although only two papers reported AUS/FLUS subcategories in CNB results, a proportional analysis could be performed for comparison with FNA. In this analysis, $72 \%$ of the nodules classified as AUS/FLUS by CNB had architectural atypia, while $70 \%$ of the nodules classified as AUS/FLUS by FNA had cellular atypia; in other words, the two tests had opposite patterns of findings. Therefore, the higher frequency of AUS/FLUS diagnoses using CNB is in line with the higher frequency of FN/SFN findings, and using CNB appears to increase the likelihood of diagnosis of FN.

\section{Similar risk of malignancy in cellular/architectural atypia and FN/SFN between CNB and FNA}

If $\mathrm{CNB}$ results in the overdiagnosis of architectural atypia or FN/ SFN, the malignancy rate would be expected to be lower for CNB than for FNA. However, the proportional meta-analysis showed no significant difference between CNB and FNA; thus, the increased diagnosis of architectural atypia or FN/SFN is not due to overdiagnosis. The potential to miss cases of FN/SFN by using FNA requires further study.

\section{Complications of CNB and FNA}

Although the proportional analysis showed no significant difference in the complication rate between CNB and FNA, the complication rate of CNB was higher than that of FNA (1.5\% vs. $0.7 \%$ ) and serious problems including injury to the carotid ar- tery were reported. Therefore, to avoid complications, caution is required when performing $\mathrm{CNB}$.

The results of this meta-analysis indicate that $\mathrm{CNB}$ has the following advantages and disadvantages. First, CNB can avoid non-diagnostic results in many cases, both in secondary biopsies after initial non-diagnostic or AUS/FLUS results and in first-line biopsies. Second, CNB results in significantly increased frequencies of architectural atypia and FN/SFN diagnoses, especially as a first-line modality, and therefore could increase the need for diagnostic surgery. However, as Yoon et al. [65] suggested, if FNA misses FN/SFN, that could be another advantage of CNB, a possibility that requires additional study. Third, the different AUS/ FLUS diagnosis patterns between FNA and CNB may explain why the proportion of AUS/FLUS was not lower on CNB than on repeated FNA in nodules initially diagnosed as AUS/FLUS on FNA. Secondary CNB in nodules diagnosed as cellular atypia by FNA may be effective because CNB may decrease the frequency of cellular atypia or suspicion for malignancy findings. However, in other cases, the increased diagnosis of architectural atypia and FN/SFN may increase the frequency of inconclusive findings. In conclusion, CNB has a definite advantage in decreasing the frequency of non-diagnostic results; however, $\mathrm{CNB}$ as a first-line biopsy technique should be selected carefully to decrease the risk of inconclusive results. Furthermore, hospitals with low rates of non-diagnostic or AUS/FLUS findings may have a minimal need for CNB.

\section{CONFLICT OF INTEREST}

No potential conflict of interest relevant to this article was reported.

\section{ORCID}

Soon-Hyun Ahn https://orcid.org/0000-0002-0759-6850

\section{SUPPLEMENTARY MATERIALS}

Supplementary materials can be found via https://doi.org/10. 21053/ceo.2020.00199.

\section{REFERENCES}

1. Park KT, Ahn SH, Mo JH, Park YJ, Park DJ, Choi SI, et al. Role of core needle biopsy and ultrasonographic finding in management of indeterminate thyroid nodules. Head Neck. 2011 Feb;33(2):160-5.

2. Cao H, Kao RH, Hsieh MC. Comparison of core-needle biopsy and fine-needle aspiration in screening for thyroid malignancy: a systematic review and meta-analysis. Curr Med Res Opin. 2016 Jul;32(7): 
1291-301.

3. Chung SR, Suh CH, Baek JH, Choi YJ, Lee JH.The role of core needle biopsy in the diagnosis of initially detected thyroid nodules: a systematic review and meta-analysis. Eur Radiol. 2018 Nov;28(11): 4909-18.

4. Li L, Chen BD, Zhu HF, Wu S, Wei D, Zhang JQ, et al. Comparison of pre-operation diagnosis of thyroid cancer with fine needle aspiration and core-needle biopsy: a meta-analysis. Asian Pac J Cancer Prev. 2014;15(17):7187-93.

5. Liu N, Meng Z, Jia Q, He X, Tian W, Tan J, et al. Ultrasound-guided core needle biopsy for differential diagnosis of thyroid nodules: a systematic review and meta-analysis. Mol Clin Oncol. 2017 Jun; 6(6):825-32.

6. Pyo JS, Sohn JH, Kang G. Core needle biopsy is a more conclusive follow-up method than repeat fine needle aspiration for thyroid nodules with initially inconclusive results: a systematic review and meta-analysis. J PatholTransl Med. 2016 May;50(3):217-24.

7. Suh CH, Baek JH, Kim KW, Sung TY, Kim TY, Song DE, et al. The role of core-needle biopsy for thyroid nodules with initially nondiagnostic fine-needle aspiration results: a systematic review and meta-analysis. Endocr Pract. 2016 Jun;22(6):679-88.

8. Suh CH, Baek JH, Lee JH, ChoiYJ, Kim KW, Lee J, et al. The role of core-needle biopsy in the diagnosis of thyroid malignancy in 4580 patients with 4746 thyroid nodules: a systematic review and metaanalysis. Endocrine. 2016 Nov;54(2):315-28.

9. Suh CH, Baek JH, Park C, Choi YJ, Lee JH. The role of core needle biopsy for thyroid nodules with initially indeterminate results on previous fine-needle aspiration: a systematic review and meta-analysis. AJNR Am J Neuroradiol. 2017 Jul;38(7):1421-6.

10. Trimboli P, Giovanella L. Reliability of core needle biopsy as a second-line procedure in thyroid nodules with an indeterminate fineneedle aspiration report: a systematic review and meta-analysis. Ultrasonography. 2018 Apr;37(2):121-8.

11. Wolinski K, Stangierski A, Ruchala M. Comparison of diagnostic yield of core-needle and fine-needle aspiration biopsies of thyroid lesions: systematic review and meta-analysis. Eur Radiol. 2017 Jan; 27(1):431-6.

12. Jung CK, Min HS, Park HJ, Song DE, Kim JH, Park SY, et al. Pathology reporting of thyroid core needle biopsy: a proposal of the Korean Endocrine Pathology Thyroid Core Needle Biopsy Study Group. J PatholTransl Med. 2015 Jul;49(4):288-99.

13. Choi SH, Baek JH, Lee JH, Choi YJ, Hong MJ, Song DE, et al. Thyroid nodules with initially non-diagnostic, fine-needle aspiration results: comparison of core-needle biopsy and repeated fine-needle aspiration. Eur Radiol. 2014 Nov;24(11):2819-26.

14. Choi YJ, Baek JH, Suh CH, Shim WH, Jeong B, Kim JK, et al. Coreneedle biopsy versus repeat fine-needle aspiration for thyroid nodules initially read as atypia/follicular lesion of undetermined significance. Head Neck. 2017 Feb;39(2):361-9.

15. Hong SH, Lee H, Cho MS, Lee JE, Sung YA, Hong YS. Malignancy risk and related factors of atypia of undetermined significance/follicular lesion of undetermined significance in thyroid fine needle aspiration. Int J Endocrinol. 2018 Jul;2018:4521984.

16. Lee SH, Kim MH, Bae JS, Lim DJ, Jung SL, Jung CK. Clinical outcomes in patients with non-diagnostic thyroid fine needle aspiration cytology: usefulness of the thyroid core needle biopsy. Ann Surg Oncol. 2014 Jun;21(6):1870-7.

17. Na DG, Kim JH, Sung JY, Baek JH, Jung KC, Lee H, et al. Coreneedle biopsy is more useful than repeat fine-needle aspiration in thyroid nodules read as nondiagnostic or atypia of undetermined significance by the Bethesda system for reporting thyroid cytopathology. Thyroid. 2012 May;22(5):468-75.

18. Na DG, Min HS, Lee H,Won JK, Seo HB, Kim JH. Role of core needle biopsy in the management of atypia/follicular lesion of undeter- mined significance thyroid nodules: comparison with repeat fine-needle aspiration in subcategory nodules. Eur Thyroid J. 2015 Sep;4(3): 189-96.

19. ParkVY, Kim EK, Kwak JY, Yoon JH, Moon HJ. Malignancy risk and characteristics of thyroid nodules with two consecutive results of atypia of undetermined significance or follicular lesion of undetermined significance on cytology. Eur Radiol. 2015 Sep;25(9):2601-7.

20. Yeon JS, Baek JH, Lim HK, Ha EJ, Kim JK, Song DE, et al. Thyroid nodules with initially nondiagnostic cytologic results: the role of core-needle biopsy. Radiology. 2013 Jul;268(1):274-80.

21. Yoon JH, Kim EK, Kwak JY, Moon HJ. Non-diagnostic thyroid nodules after application of the Bethesda system: a study evaluating the interval for repeat aspiration for non-diagnostic results. Acta Radiol. 2018 Mar;59(3):305-12.

22. Yoon JH, Kwak JY, Moon HJ, Kim EK. Ultrasonography-guided core needle biopsy did not reduce diagnostic lobectomy for thyroid nodules diagnosed as atypia of undetermined significance/follicular lesion of undetermined significance. Ultrasound Q. 2019 Sep;35(3): 253-8.

23. Ahn HS, Seo M, Ha SM, Kim HS. Comparison of the diagnostic efficacy of ultrasound-guided core needle biopsy with 18- versus 20gauge needles for thyroid nodules. J Ultrasound Med. 2018 Nov; 37(11):2565-74.

24. Ahn SH, Park SY, Choi SI. Comparison of consecutive results from fine needle aspiration and core needle biopsy in thyroid nodules. Endocr Pathol. 2017 Dec;28(4):332-8.

25. Chang H, Lee E, Lee H, Choi J, Kim A, Kim BH. Comparison of diagnostic values of thyroid aspiration samples using liquid-based preparation and conventional smear: one-year experience in a single institution. APMIS. 2013 Feb;121(2):139-45.

26. Choe J, Baek JH, Park HS, Choi YJ, Lee JH. Core needle biopsy of thyroid nodules: outcomes and safety from a large single-center single-operator study. Acta Radiol. 2018 Aug;59(8):924-31.

27. Choe JY, Kwak Y, Kim M, Chung YR, Kim HJ, Kim YK, et al. Utility of a formatted pathologic reporting system in thyroid core needle biopsy: a validation study of 1998 consecutive cases. Clin Endocrinol (Oxf). 2018 Jan;88(1):96-104.

28. Choi SH, Han KH, Yoon JH, Moon HJ, Son EJ, Youk JH, et al. Factors affecting inadequate sampling of ultrasound-guided fine-needle aspiration biopsy of thyroid nodules. Clin Endocrinol (Oxf). 2011 Jun;74(6):776-82.

29. Chong Y, Baek KH, Kim JY, Kim TJ, Lee EJ, Kang CS. Comparison of EASYPREP(R) and SurePath(R) in thyroid fine-needle aspiration. Diagn Cytopathol. 2016 Apr;44(4):283-90.

30. Chung SR, Baek JH, Lee JH, Lee YM, Sung TY, Chung KW, et al. Risk of malignancy according to the sub-classification of atypia of undetermined significance and suspicious follicular neoplasm categories in thyroid core needle biopsies. Endocr Pathol. 2019 Jun; 30(2):146-54.

31. Chung SR, Baek JH, Park HS, Choi YJ, Sung TY, Song DE, et al. Ultrasound-pathology discordant nodules on core-needle biopsy: malignancy risk and management strategy. Thyroid. 2017 May;27(5): 707-13.

32. Hong MJ, Na DG, Baek JH, Sung JY, Kim JH. Cytology-ultrasonography risk-stratification scoring system based on fine-needle aspiration cytology and the Korean-Thyroid Imaging Reporting and Data System. Thyroid. 2017 Jul;27(7):953-9.

33. Hong MJ, Na DG, Kim SJ, Kim DS. Role of core needle biopsy as a first-line diagnostic tool for thyroid nodules: a retrospective cohort study. Ultrasonography. 2018 Jul;37(3):244-53.

34. Hyeon J, Ahn S, Shin JH, Oh YL. The prediction of malignant risk in the category "atypia of undetermined significance/follicular lesion of undetermined significance" of the Bethesda System for Reporting Thyroid Cytopathology using subcategorization and BRAF mutation 
results. Cancer Cytopathol. 2014 May;122(5):368-76.

35. Jung CK, Lee A, Jung ES, Choi YJ, Jung SL, Lee KY. Split sample comparison of a liquid-based method and conventional smears in thyroid fine needle aspiration. Acta Cytol. 2008 May-Jun;52(3): 313-9.

36. Jung SJ, Kim DW, Baek HJ. Comparison study of the adequacy and pain scale of ultrasound-guided fine-needle aspiration of solid thyroid nodules with a 21- or 23-gauge needle for liquid-based cytology: a single-center study. Endocr Pathol. 2018 Mar;29(1):30-4.

37. Kim DL, Song KH, Kim SK. High prevalence of carcinoma in ultrasonography-guided fine needle aspiration cytology of thyroid nodules. Endocr J. 2008 Mar;55(1):135-42.

38. Kim DW, Choo HJ, Park JS, Lee EJ, Kim SH, Jung SJ, et al. Ultrasonography-guided fine-needle aspiration cytology for thyroid nodules: an emphasis on one-sampling and biopsy techniques. Diagn Cytopathol. 2012 May;40 Suppl 1:E48-54.

39. Kim DW, Lee EJ, Kim SH, Kim TH, Lee SH, Kim DH, et al. Ultrasound-guided fine-needle aspiration biopsy of thyroid nodules: comparison in efficacy according to nodule size. Thyroid. 2009 Jan;19(1): 27-31.

40. Kim JH, Na DG, Lee H. Ultrasonographic echogenicity and histopathologic correlation of thyroid nodules in core needle biopsy specimens. Korean J Radiol. 2018 Jul-Aug;19(4):673-81.

41. Kim M, Kim JE, Kim HJ, Chung YR, Kwak Y, Park SY. Cytologic diagnosis of noninvasive follicular thyroid neoplasm with papillary-like nuclear features and its impact on the risk of malignancy in the Bethesda system for reporting thyroid cytopathology: an institutional experience. J Pathol Transl Med. 2018 May;52(3):171-8.

42. Kim SY, Kim EK, Moon HJ,Yoon JH, Kwon HJ, Song MK, et al. Combined use of conventional smear and liquid-based preparation versus conventional smear for thyroid fine-needle aspiration. Endocrine. $2016 \mathrm{Jul} ; 53(1): 157-65$.

43. Kim YH, Kwon HJ, Kim EK, Kwak JY, Moon HJ, Yoon JH. Applying ultrasound-guided core needle biopsy for diagnosis of thyroid masses: preliminary results from a single institution. J Ultrasound Med. 2015 Oct;34(10):1801-8.

44. Koh J, Moon HJ, Kim EK, Kwak JY, Yoon JH.The 5-tiered categorization system for reporting cytology is sufficient for management of patients with thyroid nodules compared to the 6-tiered Bethesda system. Endocrine. 2016 Aug;53(2):489-96.

45. Lee MJ, Hong SW, Chung WY, Kwak JY, Kim MJ, Kim EK. Cytological results of ultrasound-guided fine-needle aspiration cytology for thyroid nodules: emphasis on correlation with sonographic findings. Yonsei Med J. 2011 Sep;52(5):838-44.

46. Lee YB, Cho YY, Jang JY, Kim TH, Jang HW, Chung JH, et al. Current status and diagnostic values of the Bethesda system for reporting thyroid cytopathology in a papillary thyroid carcinoma-prevalent area. Head Neck. 2017 Feb;39(2):269-74.

47. Moon HJ, Kim EK, Kwak JY. Malignancy risk stratification in thyroid nodules with benign results on cytology: combination of thyroid imaging reporting and data system and Bethesda system. Ann Surg Oncol. 2014 Jun;21(6):1898-903.

48. MoonWJ, Baek JH, Choi JW, Kim YJ, Ha EJ, Lim HK, et al.The value of gross visual assessment of specimen adequacy for liquid-based cytology during ultrasound-guided, fine-needle aspiration of thyroid nodules. Endocr Pract. 2015 Nov;21(11):1219-26.

49. Nam-Goong IS, Kim HY, Gong G, Lee HK, Hong SJ, Kim WB, et al. Ultrasonography-guided fine-needle aspiration of thyroid incidentaloma: correlation with pathological findings. Clin Endocrinol (Oxf). 2004 Jan;60(1):21-8.

50. Park SY, Hahn SY, Shin JH, Ko EY, OhYL. The diagnostic performance of thyroid US in each category of the Bethesda system for reporting thyroid cytopathology. PLoS One. 2016 Jun;11(6):e0155898.

51. Park VY, Lee HS, Kim EK, Kwak JY, Yoon JH, Moon HJ. Frequencies and malignancy rates of 6-tiered Bethesda categories of thyroid nodules according to ultrasound assessment and nodule size. Head Neck. 2018 Sep;40(9):1947-54.

52. Seok JY, An J, Cho HY. Improvement of diagnostic performance of pathologists by reducing the number of pathologists responsible for thyroid fine needle aspiration cytology: an institutional experience. Diagn Cytopathol. 2018 Jul;46(7):561-7.

53. Song JY, Chu YC, Kim L, Park IS, Han JY, Kim JM. Reclassifying formerly indeterminate thyroid FNAs using the Bethesda system reduces the number of inconclusive cases. Acta Cytol. 2012;56(2): 122-9.

54. Suh CH, Baek JH, Choi YJ, KimTY, SungTY, Song DE, et al. Efficacy and safety of core-needle biopsy in initially detected thyroid nodules via propensity score analysis. Sci Rep. 2017 Aug;7(1):8242.

55. Suh CH, Baek JH, Lee JH, Choi YJ, Kim JK, Sung TY, et al. The role of core-needle biopsy as a first-line diagnostic tool for initially detected thyroid nodules. Thyroid. 2016 Mar;26(3):395-403.

56. Sung JY, Na DG, Kim KS, Yoo H, Lee H, Kim JH, et al. Diagnostic accuracy of fine-needle aspiration versus core-needle biopsy for the diagnosis of thyroid malignancy in a clinical cohort. Eur Radiol. 2012 Jul;22(7):1564-72.

57. Yoo RE, Kim JH, Jang EH, Jo SW, Kang KM, Yun TJ, et al. Prediction of nondiagnostic results in fine-needle aspiration of thyroid nodules: utility of on-site gross visual assessment of specimens for liquid-based cytology. Endocr Pract. 2018 Oct;24(10):867-74.

58. Chae IH, Kim EK, Moon HJ,Yoon JH, Park VY, Kwak JY. Ultrasoundguided fine needle aspiration versus core needle biopsy: comparison of post-biopsy hematoma rates and risk factors. Endocrine. $2017 \mathrm{Jul}$; 57(1):108-14.

59. Kim SY, Lee HS, Moon J, Kim EK, Moon HJ, Yoon JH, et al. Fine-needle aspiration versus core needle biopsy for diagnosis of thyroid malignancy and neoplasm: a matched cohort study. Eur Radiol. 2017 Feb;27(2):801-11.

60. Lee YJ, Kim DW, Jung SJ, Baek HJ. Factors that influence sample adequacy in liquid-based cytology after ultrasonography-guided fine-needle aspiration of thyroid nodules: a single-center study. Acta Cytol. 2018;62(4):253-8.

61. Kim SD, Han SH, Jeong WJ, Kim H, Ahn SH. Differences in Clinical features between subcategories of "atypia/follicular lesion of undetermined significance”. Endocr Pathol. 2017 Sep;28(3):247-52.

62. Kim SJ, Roh J, Baek JH, Hong SJ, Shong YK, Kim WB, et al. Risk of malignancy according to sub-classification of the atypia of undetermined significance or follicular lesion of undetermined significance (AUS/FLUS) category in the Bethesda system for reporting thyroid cytopathology. Cytopathology. 2017 Feb;28(1):65-73.

63. Park HJ, Moon JH, Yom CK, Kim KH, Choi JY, Choi SI, et al. Thyroid "atypia of undetermined significance" with nuclear atypia has high rates of malignancy and BRAF mutation. Cancer Cytopathol. 2014 Jul;122(7):512-20.

64. Yoon JH, Kwon HJ, Kim EK, Moon HJ, Kwak JY. Subcategorization of atypia of undetermined significance/follicular lesion of undetermined significance (AUS/FLUS): a study applying Thyroid Imaging Reporting and Data System (TIRADS). Clin Endocrinol (Oxf). 2016 Aug;85(2):275-82.

65. Yoon RG, Baek JH, Lee JH, Choi YJ, Hong MJ, Song DE, et al. Diagnosis of thyroid follicular neoplasm: fine-needle aspiration versus core-needle biopsy. Thyroid. 2014 Nov;24(11):1612-7.

66. Ha EJ, Baek JH, Lee JH, Kim JK, Choi YJ, Sung TY, et al. Complications following US-guided core-needle biopsy for thyroid lesions: a retrospective study of 6,169 consecutive patients with 6,687 thyroid nodules. Eur Radiol. 2017 Mar;27(3):1186-94.

67. Jeong EJ, Chung SR, Baek JH, Choi YJ, Kim JK, Lee JH. A comparison of ultrasound-guided fine needle aspiration versus core needle biopsy for thyroid nodules: pain, tolerability, and complications. En- 
docrinol Metab (Seoul). 2018 Mar;33(1):114-20.

68. Kim HJ, Kim YK, Moon JH, Choi JY, Choi SI. Thyroid core needle biopsy: patients' pain and satisfaction compared to fine needle aspiration. Endocrine. 2019 Aug;65(2):365-70.

69. Haugen BR, Alexander EK, Bible KC, Doherty GM, Mandel SJ, Nikiforov YE, et al. 2015 American Thyroid Association management guidelines for adult patients with thyroid nodules and differentiated thyroid cancer: the American Thyroid Association Guidelines Task Force on Thyroid Nodules and Differentiated Thyroid Cancer. Thyroid. 2016 Jan;26(1):1-133.

70. Cibas ES,Ali SZ; NCIThyroid FNA State of the Science Conference.
The Bethesda system for reporting thyroid cytopathology. Am J Clin Pathol. 2009 Nov;132(5):658-65.

71. Ahn SH, Kim SD, Jeong WJ. Comparison of risk of malignancy in a subgroup with atypia of undetermined significance/follicular lesion of undetermined significance: a meta-analysis. Head Neck. 2017 Aug;39(8):1699-710.

72. Johnson DN, Cavallo AB, Uraizee I, Tanager K, Lastra RR, Antic T, et al. A proposal for separation of nuclear atypia and architectural atypia in Bethesda category III (AUS/FLUS) based on differing rates of thyroid malignancy. Am J Clin Pathol. 2019 Jan;151(1):86-94. 